\title{
Atmospheric excitement, customers' moods and gender: A study of young shoppers
}

\author{
L. Lucia-Palacios, R. Pérez-López (iD) and Y. Polo-Redondo \\ Facultad de Economía y Empresa, Department of Marketing and Market Research, University of Zaragoza, \\ Zaragoza, Spain
}

\begin{abstract}
This paper aims to demonstrate how both incidental moods and gender can moderate the relationship between the level of excitement triggered by a mall environment and shopping behaviour. Our method is based on a $4 \times 2$ between subjects experiment with a final sample of 377 Spanish undergraduates. The study analyses four incidental moods that differ in the dimensions of valence and arousal, and their interaction effects with two atmospheric scenarios in a mall (exciting versus non-exciting atmospheres). Our findings support mood regulation theory for positive low-arousal individuals, and reject this theory for the rest of mood conditions. Additionally, arousal reduces customers' cognitive capabilities, confirming previous research. This means that high-arousal shoppers are not influenced by a mall environment. Finally, gender differences are only found within more frequent shoppers and for negative low-arousal (NLA) shoppers. Managerial implications are provided regarding the creation of relaxing areas or the stimulation of shoppers.
\end{abstract}

\section{ARTICLE HISTORY}

Received 26 February 2017

Accepted 2 June 2017

\section{KEYWORDS}

Shopping behaviour; atmospherics; incidental moods; shopping malls; mood regulation theory

\section{Introduction}

Shopping is an activity in which people not only take into account utilitarian aspects of goods or services but also want to be entertained and emotionally affected. Consequently, mall managers have often created exciting atmospheres to encourage shopping behaviour by modifying atmospheric variables.

Previous research has identified a positive relationship between excitement and shopping behaviour, detecting that exciting scenarios lead to greater patronage intentions, positive word-of-mouth and intentions to return (Jayawardhena \& Wright, 2009; Wakefield \& Baker, 1998). However, others have detected confusing effects of exciting atmospheres on behaviour. This excitement may positively influence some behavioural variables, such as satisfaction, but not others, such as spending (Morrison, Gan, Dubelaar, \& Oppewal, 2011). These contradictions show that further research is needed on this topic. Some papers have demonstrated that consumer-related characteristics, such as shopping orientation and expectations, can moderate the effects of store characteristics on shopping behaviour (Holmqvist \& Lunardo, 2015; Massara, Liu, \& Melara, 2010; Vieira \& Torres, 2014). However, might there be 
additional customer-related characteristics that can change the relationship between atmospheric excitement and shopping behaviour? This paper focuses on incidental moods and gender as customer-related characteristics that can be relevant to explain changes in this relationship.

Moods have been widely studied by research on the effects of atmospheric cues on shopping behaviour finding that atmospheric variables can affect moods, which in turn influence time and money spent in the store, satisfaction and repatronage intentions (Das, 2016; Furnham \& Milner, 2013; Orth \& Wirtz, 2014). This previous research has found that atmospheric variables can affect moods, which in turn influence time and money spent in the store, satisfaction and repatronage intentions. However, little is known on how incidental moods, felt immediately before the shopping experience, can influence the relationship between atmospheric cues and shopping behaviour. Mano (1999) demonstrated that bored shoppers had greater intentions to purchase than distressed when the atmosphere was pleasant, and Puccinelli, Deshpande, and Isen (2007) found that shoppers preferred happy atmospheres when this feature matched their moods. Nevertheless, this prior research addresses neither the effects of an exciting atmosphere on behaviour nor the possible influence of moods regarding atmospheric excitement. Furthermore, the literature has usually differentiated between good and bad mood. However, there are additional dimensions of moods that can be relevant for shopping behaviour, such as arousal (Wirtz, Mattila, \& Tan, 2000).

Gender is a relevant customer-related characteristic that has been widely analysed in the marketing field (Davis, Lang, \& San Diego, 2014) for two reasons: it is an important factor in understanding consumer behaviour and is a variable widely used by companies for market segmentation. According to previous research, women tend be more recreationally oriented, and more easily influenced by hedonic atmospheric cues (Borges, Babin, \& Spielmann, 2013; Kotzé, North, Stols, \&Venter, 2012). However, could females and males differ in their shopping behaviour depending on the level of atmospheric excitement?

As a consequence, the aim of this research is to demonstrate that the effect of atmospheric excitement on shopping behaviour in a mall setting may not be stable but may depend on incidental moods and gender. This general objective leads to two specific goals: first, to demonstrate that both valence and arousal of incidental moods can moderate the relationship between the level of excitement triggered by a mall atmosphere and shopping outcomes and, second, to show how the effects of this excitement on shopping behaviour in a mall setting can change depending on gender.

Mood regulation theory (Di Muro \& Murray, 2012; Kemp \& Kopp, 2011; Kim, Park, \& Schwartz, 2010) provides a useful theoretical framework to argue the interactions between atmospheric variables and moods. According to this theory, customers in positive higharousal (PHA) and positive low-arousal moods (PLA) may prefer atmospheres that help them maintain their mood, while shoppers in a negative high-arousal (NHA) and NLA mood may want atmospheres that help them become positive.

Our methodology is based on an experiment carried out in a laboratory setting in which 377 students from a north-eastern Spanish university participated. We focus on a sample of young customers because they represent a segment that frequently attends shopping centres and provides a high perspective of future profitability for companies (Grant \& Waite, 2003; Haytko \& Baker, 2004). 
Our research contributes to the marketing field in several ways. First, we demonstrate that arousal of incidental moods with the same valence moderates the relationship between the level of excitement triggered by a mall atmosphere and shopping behaviour. Second, we extend mood regulation theory to explain shopping behaviour in an exciting (vs. nonexciting) mall atmosphere providing evidences about in which mood condition is confirmed. Specifically, it is found that a high atmospheric excitement creates a discomfort for PLA shoppers what leads to a less positive behaviour. Third, we show that gender is important to explain consumer behaviour in a mall and that the benefits of an exciting atmosphere are higher for women that feel bored.

The rest of the paper is organized as follows. The following section reviews the theoretical background existent in the literature about atmospheric cues, moods and shopping behaviour and proposes the hypotheses to be tested. Afterwards, we will explain the experiment to continue presenting our results. Finally, we will discuss our results, highlighting our main conclusions, managerial implications and possible future lines of research.

\section{Theoretical framework}

\subsection{Atmospheric cues and shopping behaviour}

A vast body of research has demonstrated that store atmospheric factors play a critical role in shopping behaviour, through both cognitive and affective processes. Most research has addressed the consequences of atmospheric factors on behavioural outcomes, such as propensity to buy (Turley \& Milliman, 2000), time spent on the visit (Spies, Hesse, \& Loesch, 1997), money spent (Sherman, Mathur, \& Smith, 1997), patronage intentions (Wakefield \& Baker, 1998), satisfaction (McKinney, 2004), store attitude (Yoo, Park, \& Macinnis, 1998), impulse buying behaviour (Mohan, Sivakumaran, \& Sharma, 2013) and loyalty (Molina, Martín, Santos, \& Aranda, 2009). Most of these articles have focused on the effects of pleasant or exciting atmospheres on shopping behaviour. Pleasantness refers to positive affective states, while excitement is the level of stimulation of an affective state (Mehrabian \& Russell, 1974). Atmospheric excitement involves a colourful, saturated, lively and light-filled mall environment (Holmqvist \& Lunardo, 2015; Kaltcheva \& Weitz, 2006), while a pleasant atmosphere may be colourful, but not saturated, lightly and light-filled. In contrast a pleasant atmosphere is relaxing and peaceful.

Whilst the effects of pleasant atmospheres are stable in the literature leading to favourable behaviours, such as more satisfaction, more money spent in the store, greater positive emotions or greater value (Fernandes \& Neves, 2014; Law, Wong, \& Yip, 2012; Molina et al., 2009; Spies et al., 1997), the effects of exciting atmospheres are less consistent (Massara et al., 2010; Morrison et al., 2011). Sherman et al. (1997) found that an exciting atmosphere increased money and time spent and the number of items purchased. Donovan and Rossiter (1982) found that the excitement triggered by retail environment had a positive influence on shopping behaviour only in pleasant retail environments. However, Morrison et al. (2011) detected a positive effect of atmospheric excitement on customers' satisfaction but not on spending.

These contradictions made some authors to include some moderating variables that could explain the different results of the effect of the atmosphere and shopping behaviour. Kaltcheva and Weitz (2006) included motivational orientations as a moderating variable in 
the relationship between atmospheric excitement and shoppers' pleasure. An exciting atmosphere had a positive effect on shopping behaviour for those with recreationally oriented objectives, but a negative impact on those with a task-oriented goal. Massara et al. (2010) used as moderating variable the consumer's expectations, finding that the level of excitement elicited by a virtual store atmosphere led to a better behaviour only if this excitement matched the consumer's expectations. Therefore, the influence of atmospheric excitement on shopping behaviour can be moderated by different customer characteristics. Can incidental moods and gender act as moderating variables?

\subsection{Incidental moods}

Incidental moods are defined as the feelings experienced by the customer prior to the shopping activity (Luong, 2005) originated from external factors unrelated to the shopping experience with no specifiable causes (Garg, Inman, \& Mittal, 2005; Pocheptsova \& Novemsky, 2010). Marketing literature has often distinguished several types of incidental moods depending on two dimensions: valence and arousal. The traditional view of mood has focused on valence differentiation, positive versus negative mood (Maier, Wilken, Schneider, \& Kelemci-Schneider, 2012; Watson, Clark, \& Tellegen, 1988). However, recent research has demonstrated that two different affective states in arousal but with the same valence can drive different judgments and decisions (Di Muro \& Murray, 2012; Kim et al., 2010). Mehrabian and Russell (1974) defined arousal as a dimension of affective states that'ranges from sleepy to frantic excitement.' As a consequence, we can realize that the excitement triggered by a mall atmosphere is similar to the dimension of arousal of incidental moods.

Taken into account valence and arousal, individuals will be able to feel a PHA mood, related to feelings of enthusiasm, elation and excitement; a PLA mood, characterized by calmness and peacefulness; an NHA mood, which reflects distress and nervousness; and an NLA mood, related to sadness and boredom (Kim et al., 2010; Watson et al., 1988; Zwosta, Hommel, Goschke, \& Fischer, 2013).

Little is known about the role of these four types of moods in the relationship between shopping atmosphere and customer shopping behaviour. Previous research has found that the level of pleasantness of the atmosphere can interact with moods and explain differences in shopping behaviour (Mano, 1999; Puccinelli et al., 2007). Mano (1999) found that bored shoppers had greater intentions to purchase than distressed individuals when the store atmosphere was good, while the effect was the contrary when the atmosphere was catalogued as bad. This author took into account the pleasantness triggered by a store atmosphere when shoppers were in a negative mood but differed in the level of arousal. Puccinelli et al. (2007) analysed the moderating effect of only mood valence and found that happy store atmospheres could make customers feel more comfortable, only if they were in a positive mood, while they preferred sombre contexts if they were in a sad mood. Then, previous research has focused on the interaction effect of atmospheric pleasantness and moods. However, no research has addressed the interaction effects of atmospheric excitement and moods in terms of both valence and arousal.

Mood regulation theory posits two basic assumptions: (1) people are motivated to maintain positive moods and (2) they are motivated to mitigate negative moods (Di Muro \& Murray, 2012; Kemp \& Kopp, 2011; Kim et al., 2010; Meloy, 2000; Zillman, Hezel, \& Medoff, 1980). For instance, Zillman et al. (1980) found that consumers preferred a TV show that 
offered them relief from negative affective experiences. Additionally, Meloy (2000) demonstrated that consumers in a pleasant mood preferred to maintain their good mood even though the option taken led them to a poor choice. According to Di Muro and Murray (2012), if consumers were in a PHA mood (e.g. enthusiasm), they preferred an arousing product that helped them maintain that mood. Furthermore, if they were in an NLA mood (e.g. boredom), they also preferred an arousing product, since this product helped them change an unpleasant mood into a positive one. In contrast, both consumers in a PLA mood, and consumers in a NHA mood preferred non-arousing products. The former looked for mood maintenance, while the latter wished to change that unpleasant mood into a positive one.

We can extrapolate this reasoning to our study context that is differentiation between an exciting atmosphere (EA) and a non-exciting atmosphere (NEA). Shoppers in a PHA mood would prefer an exciting atmosphere, since they are likely to feel more comfortable with that state. Puccinelli et al.'s (2007) findings reinforce this argument, since people feeling lively and joyful would find that an exciting atmosphere could match their mood, which results in greater comfortability. The same argument, but in the contrary sense, operates when shoppers feel a PLA mood. They would prefer an NEA that helps them maintain that mood. However, for NLA and high-arousal shoppers, mood regulation theory predicts that shoppers would prefer an atmosphere with mood-lifting capabilities, that could help them change their negative prior mood. Thus, shoppers in a NLA mood would feel more comfortable in an exciting atmosphere, while those in an NHA mood would feel better in an NEA. This is consistent with Mano (1999) results, according to which, bored customers preferred a pleasant atmosphere. As a consequence, we formulate the following hypotheses:

H1: Atmospheric excitement will have a positive effect on shopping behaviour for (a) shoppers in a NLA mood, and (b) shoppers in a positive-high arousal mood.

H2: Atmospheric excitement will have a negative effect on shopping behaviour for (a) shoppers in a PLA mood, and (b) shoppers in a NHA mood.

\subsection{Gender}

Despite the fact that males' and females' lifestyles have undergone important changes during the last 30 years in developed countries, there are still relevant gender differences in shopping behaviour that have been documented in the literature (Borges et al., 2013; Grewal, Baker, Levy, \& Voss, 2003; Kuruvilla, Joshi, \& Shah, 2009). This prior research has generally found that women have a more favourable shopping behaviour than men, since they are more involved shoppers, go shopping more often and are more hedonic. Grewal et al. (2003) demonstrated that men had more negative waiting expectations than women because they are more time-conscious. Furthermore, Kuruvilla et al. (2009) demonstrated that women had a more positive general attitude towards shopping.

Additionally, Borges et al. (2013) found that gender had a moderating effect on the relationship between a hedonic store atmosphere and shopping behaviour, this relationship being stronger for women. The argument is that they respond more favourably to the hedonic aspects of the shopping atmosphere and obtain greater value from them, which can positively influence their shopping behaviour (Kotzé et al., 2012; Meyers-Levy \& Sternthal, 1991; Pan \& Zinkhan, 2006). Women usually extend the shopping experience and include hedonic aspects of the atmosphere when they assess the quality of the experience (Johnstone 
\& Conroy, 2005; Polegato \& Zaichowsky, 1994). Similarly, we can state that the effect of atmospheric excitement on shopping behaviour will be stronger for women. Exciting atmospheres are usually characterized by hedonic details in order to trigger hedonic and exciting feelings to shoppers (Kaltcheva \& Weitz, 2006; Wirtz et al., 2000). Thus, women are more likely to be influenced by these exciting and hedonic cues, and consequently change their shopping behaviour. Taking into account the different influence of atmospheric cues on shopping behaviour depending on moods, we propose our next hypotheses:

H3: The positive effect of atmospheric excitement on shopping behaviour will be stronger for females than males when they are in PHA and NLA mood.

H4: The negative effect of atmospheric excitement on shopping behaviour will be stronger for females than males when they are in NHA and PLA mood.

\section{Methodology}

\subsection{Participants, design and procedure}

We conducted a 4 (incidental mood: PHA, PLA, NHA vs. NLA) $\times 2$ (EA vs. NEA) betweensubjects experiment during November 2013. Four hundred and forty-six undergraduate students from a Spanish university participated in the study. As an incentive, they took part in a raffle for a coupon worth 60 euros to spend in a well-known Spanish department store. This segment of young customers is one of the most important groups of customers that visit shopping centres and has a great potential for the future profits of companies. However, the literature on this segment is scant (Gilboa \& Vilnai-Yavetz, 2013; Haytko \& Baker, 2004). After a purification process, 377 questionnaires were valid. $61.6 \%$ were women, the average age was 21.05 and $82.9 \%$ of them went to the shopping centre at least once a month.

Respondents were randomly assigned to one of the eight conditions. The experiment had two different stages: mood induction and manipulation of atmospheric excitement. The experimenter informed participants that they would be asked to complete several unrelated tasks and they were informed about the impossibility of going back once they had completed each one.

Participants were first asked to put a set of 10 words into alphabetical order with the aim of removing any mood differences due to extraneous factors (Wegener, Petty, \& Smith, 1995). Following previous research (Kim et al., 2010; Puccinelli et al., 2007; Zwosta et al., 2013) mood induction was achieved through two techniques: video exposure and descriptions of past life experiences. First, they watched a video that evoked the corresponding mood state and after watching the video, participants were asked to provide a detailed written description of one life experience that had made them feel each mood. These videos were based on previous research and a pre-test was conducted (Pham, Hung, \& Gorn, 2011; Zwosta et al., 2013).

Once the participants had written their task, they were asked to indicate how they were feeling on a seven-point scale. Finally, participants were randomly exposed to one of two pictures depicting an exciting or an NEA at a mall. Differences in the level of excitement triggered by a mall atmosphere depend on: lighting, perceived crowding and colours, according to previous research. Bright lights, moderate crowding and warmer and more saturated colours are present in the exciting condition, whilst soft lights, minimum levels of crowding 
and cooler and less saturated colours form the non-exciting condition (Holmqvist \& Lunardo, 2015; Kaltcheva \& Weitz, 2006; Mehrabian \& Russell, 1974; Van Rompay, Krooshoop, Verhoeven, \& Pruyn, 2012). After having seen the image, participants were asked about the level of excitement that the image triggered and about their shopping behaviour. The images employed in the experiment can be seen in the Appendix.

\subsection{Pre-test}

In order to determine whether the videos and the images effectively evoked the feelings they were supposed to trigger, we conducted a pre-test within 80 participants (53 were women and the average age was 22.23). They rated the extent to which each video had evoked the corresponding mood on a seven-point scale. Additionally, we asked them to rate the level of excitement that the two images transmitted on a seven-point semantic differential scale. In each mood condition, results of analysis of variance (ANOVA) showed that the induction was successful. In the PHA condition, participants scored higher on feelings of enthusiasm, excitement and activation $\left(F_{3.79}=26.407, p<0.01\right.$, with $\left.\mu=5.409\right)$. The same happened in the other mood conditions: PLA ( $F_{378}=42.684, p<0.01$, with $\left.\mu=5.741\right)$, NHA $\left(F_{3.79}=34.659, p<0.01\right.$, with $\left.\mu=4.56\right)$ and NLA $\left(F_{3.79}=17.265, p<0.01\right.$, with $\left.\mu=5.038\right)$. As well as mood conditions, the atmospheric excitement was clearly different between the two images used ( $F_{1.77}=118.436, p<0.01$, with $\mu=5.388$ and $\mu=2.925$, respectively).

\subsection{Measures}

All the variables were measured by applying scales previously used in the marketing literature and adapting them to the Spanish market. Moods were measured with seven-point scales based on Kim et al. (2010) and Mano (1999) studies. The PHA mood was built with four adjectives: excited, enthusiastic, active and lively $(\alpha=0.864)$, while tranquil, peaceful, serene and calm $(\alpha=0.939)$ were used to measure the PLA mood. The NHA mood was measured with distressed, upset, nervous, anxious and distraught $(\alpha=0.899)$ and the NLA mood by bored, tired, drowsy, sluggish and sleepy $(\alpha=0.907)$. Atmospheric excitement was measured by a seven-point semantic differential scale adapted from Kaltcheva and Weitz (2006) with an acceptable value of Cronbach' Alpha for this construct ( $\alpha=0.867)$. Finally, the measure of shopping behaviour (SB) was based on the study of Donovan and Rossiter (1982), also used by Kaltcheva and Weitz (2006). Our research employs these authors' concept of shopping behaviour, defined as a general construct, including shopping enjoyment, intentions to return to the mall, time spent browsing and buying, purchase intentions and recommendation intentions. Participants had to score on a seven-point Likert scale. The items were the following: 'I would enjoy shopping in this mall', I would return to this mall', 'I would spend more time at this mall looking around or exploring this environment','I would be willing to buy things at this mall','This is a place where I might try to avoid other people and avoid having to talk to them' (reversed scoring), 'I would be willing to recommend this mall to my friends'. The reversed item was eliminated what allowed us to reach a good value of Cronbach's Alpha $(\alpha=0.904)$. Gender was a dichotomous variable being 0 for males and 1 for females. 


\section{Results}

First, as a check of the effectiveness of the mood induction, the adjective-scale ratings of mood were examined. Table 1 shows the means of each mood experienced by participants in each mood condition. An ANOVA yielded that participants in the PHA condition reported significantly higher PHA mood states $\left(F_{3.373}=142.21, p<0.01\right)$ compared to participants in the other mood conditions. Individuals in the PLA condition scored higher on the adjectives that measured the PLA mood $\left(F_{3.375}=195.23, p<0.01\right)$ and the same occurred in the NHA condition $\left(F_{3.369}=156.69, p<0.01\right)$ and in the NLA one $\left(F_{3.372}=109.23, p<0.01\right)$.

Second, the level of excitement that mall images effectively triggered was assessed. Those subjects that were assigned to the exciting atmosphere condition reported that their image significantly evoked higher atmospheric excitement $\left(F_{1.374}=322.83, p<0.01\right)$ than those exposed to non-exciting mall atmosphere, as can be seen in Table 2.

The hypotheses were tested using ANOVA. Table 3 shows the main and interaction effects of the exogenous variables on shopping behaviour (SB) for young customers. The main effect of moods on SB is not significant, while the main effect of atmospheric excitement is statistically relevant $\left(F_{1.377}=5.578, p<0.05\right)$.

Table 1. Mean adjective-scale ratings of induced mood (scale from 1 to 7 ).

\begin{tabular}{|c|c|c|c|c|c|c|c|c|}
\hline \multirow{3}{*}{$\begin{array}{l}\text { Incidental } \\
\text { mood condi- } \\
\text { tions }\end{array}$} & \multicolumn{4}{|c|}{ Positive valence } & \multicolumn{4}{|c|}{ Negative valence } \\
\hline & \multicolumn{2}{|c|}{ High-arousal } & \multicolumn{2}{|c|}{ Low-arousal } & \multicolumn{2}{|c|}{ High-arousal } & \multicolumn{2}{|c|}{ Low-arousal } \\
\hline & Mean & $(\mathrm{SD})$ & Mean & (SD) & Mean & (SD) & Mean & (SD) \\
\hline $\mathrm{PHA}$ & 5.186 & 0.893 & 3.053 & 1.032 & 2.582 & 1.188 & 2.082 & 0.924 \\
\hline PLA & 3.114 & 1.105 & 5.769 & 0.928 & 2.327 & 1.037 & 4.193 & 1.373 \\
\hline $\mathrm{NHA}$ & 2.225 & 0.980 & 1.576 & 0.704 & 4.638 & 1.237 & 2.466 & 1.298 \\
\hline NLA & 2.033 & 1.004 & 3.142 & 1.389 & 2.882 & 1.223 & 5.321 & 1.111 \\
\hline
\end{tabular}

Notes: *PHA: positive high-arousal mood; PLA: positive low-arousal mood; NHA: negative high-arousal mood; NLA: negative low-arousal mood.

Bold values refer to the mean-adjective scale ratings that match the incidental mood condition

Table 2. Mean differential semantic scale ratings for atmospheric excitement (scale from 1 to 7).

\begin{tabular}{lcc}
\hline Atmospheric arousal conditions & Mean & SD \\
\hline Exciting atmosphere (EA) & 5.332 & 1.058 \\
Non-exciting atmosphere (NEA) & 3.373 & 1.056 \\
\hline
\end{tabular}

Table 3. Results of ANOVA. Main and interaction effects of exogenous variables on SB.

\begin{tabular}{|c|c|c|c|c|c|}
\hline Shopping behaviour (SB) & d.f. & Sum of squares & Mean square & $F$ & Sig. \\
\hline \multicolumn{6}{|l|}{ Main effects } \\
\hline Mood & 3 & 4.129 & 1.376 & .736 & .531 \\
\hline $\mathrm{AE}$ & 1 & 10.437 & 10.437 & 5.578 & .019 \\
\hline Gender & 1 & 8.630 & 8.630 & 4.612 & .032 \\
\hline \multicolumn{6}{|l|}{ Interaction effects } \\
\hline Mood ${ }^{*} \mathrm{AE}$ & 3 & 29.810 & 9.937 & 5.311 & .001 \\
\hline Mood * Gender & 3 & 1.292 & .431 & .230 & .875 \\
\hline$A E^{*}$ Gender & 1 & 1.260 & 1.260 & .674 & .412 \\
\hline Mood ${ }^{*} A E^{*}$ Gender & 3 & .866 & .289 & .154 & .927 \\
\hline Error & 362 & 677.331 & 1.871 & & \\
\hline Total & 377 & 741.615 & & & \\
\hline
\end{tabular}

Notes: ${ }^{*} \mathrm{AE}$ : atmospheric excitement. 
Table 4. Mean and SD of SB (scale from 1 to 7) and significance of differences by condition.

\begin{tabular}{|c|c|c|c|c|c|c|c|c|}
\hline \multirow[b]{3}{*}{ Incidental moods } & \multicolumn{6}{|c|}{ Mall atmospheric excitement } & & \\
\hline & \multicolumn{3}{|c|}{ EA } & \multicolumn{3}{|c|}{ NEA } & \multicolumn{2}{|c|}{ ANOVA } \\
\hline & $N$ & Mean & (SD) & $N$ & Mean & (SD) & $F$ & Sig. \\
\hline$\overline{\mathrm{PHA}}$ & 45 & 4.519 & 1.405 & 34 & 4.471 & 1.401 & .023 & .881 \\
\hline PLA & 52 & 3.597 & 1.324 & 68 & 4.829 & 1.416 & 23.694 & .000 \\
\hline $\mathrm{NHA}$ & 53 & 4.248 & 1.432 & 45 & 4.630 & 1.247 & 1.940 & .167 \\
\hline NLA & 43 & 4.500 & 1.393 & 40 & 4.285 & 1.279 & .751 & .389 \\
\hline
\end{tabular}

Notes: ${ }^{*}$ SB: shopping behaviour; PHA: positive high-arousal mood; PLA: positive low-arousal mood; NHA: negative high-arousal mood; NLA: negative low-arousal mood; EA: exciting atmosphere; NEA: non-exciting atmosphere.

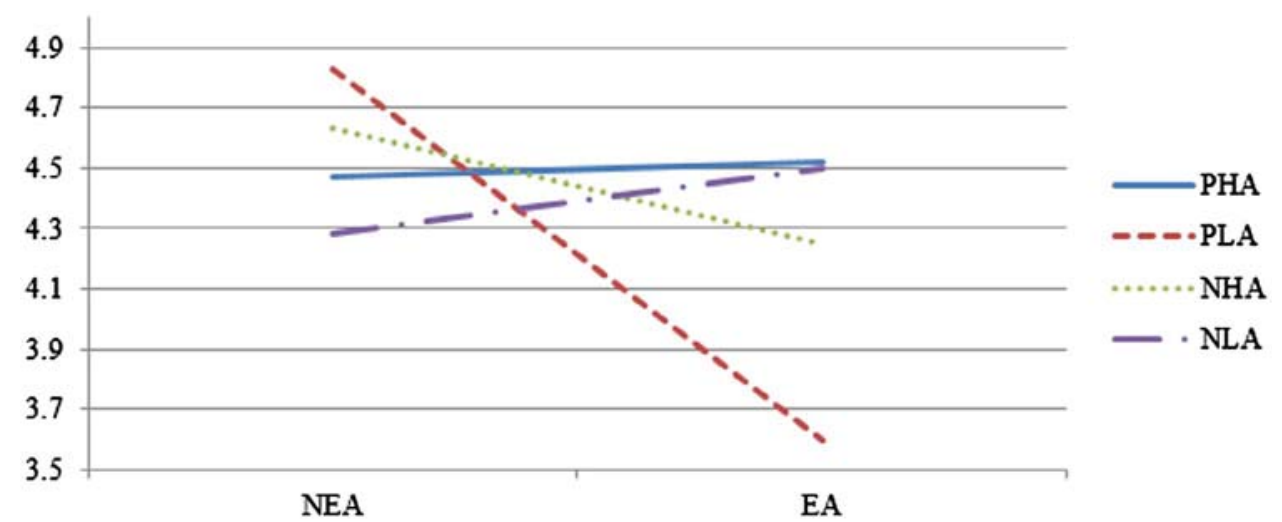

Figure 1. Two-way interaction effect of moods and atmospheric excitement on shopping behaviour. Notes: *PHA: positive high-arousal; PLA: positive low-arousal mood; NHA: negative low-arousal mood; EA: exciting atmosphere; NEA: non-exciting atmosphere.

As expected, we found a significant two-way interaction effect between moods and atmospheric excitement on shopping behaviour $\left(F_{3.377}=5.311, p<0.01\right)$. Means of shopping behaviour by experimental condition and results of ANOVA by mood condition are displayed in Table 4. $\mathrm{H} 1 \mathrm{a}$ and $\mathrm{H} 1 \mathrm{~b}$ are not confirmed, since the effect of atmospheric excitement on shopping behaviour is not significant for NLA and PHA individuals. In contrast, differences in shopping behaviour are significant for PLA individuals and H2a is confirmed as shopping behaviour improves when atmospheric excitement decreases. However, $\mathrm{H} 2 \mathrm{~b}$ is not, since the level of excitement does not significantly affect shopping behaviour for NHA individuals. Figure 1 depicts these effects.

The main effect of gender on shopping behaviour is significant, but no interaction effects were found between atmospheric excitement and gender on young customers' shopping behaviour. As a consequence $\mathrm{H} 3$ and $\mathrm{H} 4$ are not confirmed. The effects of atmospheric excitement on shopping behaviour are always more positive for women than for men regardless of moods. Nevertheless, these differences are not significant. There is an only case in which the effect proposed by $\mathrm{H} 4$ is confirmed: When shoppers are in an NLA mood and in an exciting atmosphere, the difference in shopping behaviour between females and males is slightly significant at $10 \%$, and the change in shopping behaviour is greater for women (Table 5 and Figure 2). 
Table 5. Mean and SD of SB (scale from 1 to 7) and significance of differences by condition.

\begin{tabular}{|c|c|c|c|c|c|c|c|c|c|}
\hline \multirow{2}{*}{$\begin{array}{l}\text { Incidental } \\
\text { moods }\end{array}$} & \multirow{2}{*}{$\begin{array}{c}\text { Atmospheric } \\
\text { excitement }\end{array}$} & \multicolumn{3}{|c|}{ Females } & \multicolumn{3}{|c|}{ Males } & \multicolumn{2}{|c|}{ ANOVA } \\
\hline & & $N$ & Mean & (SD) & $N$ & Mean & (SD) & $F$ & Sig. \\
\hline \multirow[t]{2}{*}{ PHA } & $E A$ & 28 & 4.595 & 1.482 & 17 & 4.392 & 1.302 & .217 & .644 \\
\hline & NEA & 11 & 4.515 & 1.725 & 23 & 4.449 & 1.261 & .016 & .900 \\
\hline \multirow[t]{2}{*}{ PLA } & EA & 29 & 3.724 & 1.275 & 21 & 3.421 & 1.401 & .635 & .429 \\
\hline & NEA & 45 & 4.948 & 1.417 & 23 & 4.638 & 1.405 & .735 & .394 \\
\hline \multirow[t]{2}{*}{$\mathrm{NHA}$} & EA & 40 & 4.383 & 1.524 & 13 & 3.833 & 1.043 & 1.461 & .232 \\
\hline & NEA & 33 & 4.677 & 1.239 & 12 & 4.500 & 1.316 & .173 & .679 \\
\hline \multirow[t]{2}{*}{ NLA } & EA & 23 & 4.848 & 1.429 & 20 & 4.100 & 1.269 & 3.248 & .079 \\
\hline & NEA & 24 & 4.347 & 1.466 & 16 & 4.094 & .927 & .376 & .543 \\
\hline
\end{tabular}

Notes: *PHA: positive high-arousal mood; PLA: positive low-arousal mood; NHA: negative high-arousal mood; NLA: negative low-arousal mood; EA: exciting atmosphere; NEA: non-exciting atmosphere.

PHA shoppers

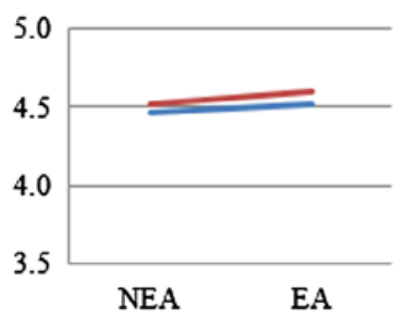

PLA shoppers

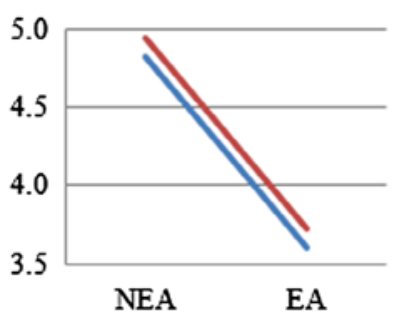

NHA shoppers

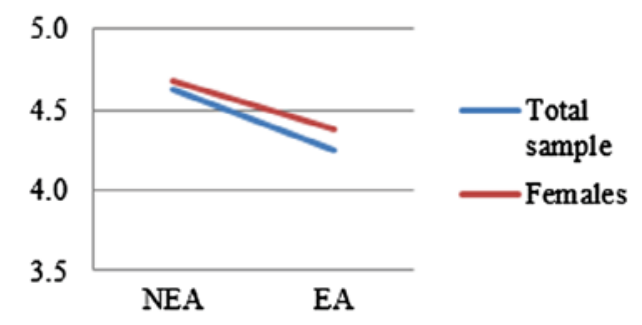

NLA shoppers

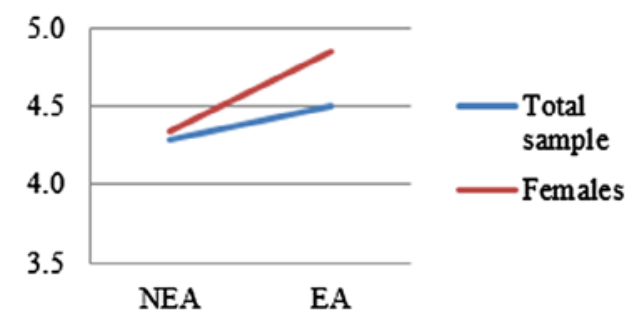

Figure 2. Two-way interaction effects of gender and atmospheric excitement on shopping behaviour by mood condition.

\section{Conclusions}

Our research proposes two main goals: to demonstrate that the effects of an exciting mall atmosphere on shopping behaviour are moderated by valence and arousal of incidental moods, and to show the influence of gender on shopping behaviour. Our research provides answers to some questions raised in the literature about the moderating effect of these variables on shopping behaviour (Davis et al., 2014; Johnstone \& Conroy, 2005). To achieve our goals, we carried out an experiment using a sample of 377 young customers.

Our analysis confirms mood regulation theory (Di Muro \& Murray, 2012; Meloy, 2000) as it demonstrates that the excitement triggered by a mall atmosphere worsens shopping behaviour for shoppers in a PLA mood. Relaxed, calm or serene shoppers prefer a NEA to maintain their quiet, peaceful and pleasant mood. The discomfort caused when approaching an exciting 
atmosphere leads them to a worse shopping behaviour. In contrast, shoppers in an NLA mood may prefer an exciting atmosphere that helps them change their negative mood into a positive one. However, although an improvement in approach behaviour is found in this kind of shoppers, this change is not significant. One explanation may be the low involvement with which NLA individuals conduct their shopping activity, as previous research has found (Mano, 1999; Pham et al., 2011). Boredom is the most common mood experienced during mall visits that is related to NLA moods. This affective state has been previously related to cognitive and attentional deficits that may lead to a negative association with the shopping task (Kass, Beede, \& Vodanovich, 2010). However, these arguments have been conceptualized in the psychological field and applied to different contexts where the role of boredom may be different. So, further research should explore the effects of NLA moods on shopping activity.

Regarding positive and NHA shoppers, the direction of the effects is consistent with mood regulation theory, and PHA shoppers' behaviour slightly improves in an exciting atmosphere, while the influence of this excitement is negative for NHA shoppers. However, these effects are not significant and enthusiastic and joyful people, as well as anxious or distressed shoppers, are not influenced by the level of atmospheric excitement. These results, although contrary to our expectations, are consistent with Mano's (1999) findings that argued that arousal restricts attention capacity and decreases cognitive effort, which leads consumers to be less sensitive to atmospheric cues, to pay less attention to the shopping experience and to show a reduced capacity for solving complex tasks (Förster, Friedman, \& Liberman, 2004; Gorn, Pham, \& Sin, 2001). More aroused individuals do not process as extensively and tend to simplify their decisions by focusing on the most prominent and remarkable features of the shopping task, without paying attention to aspects such as atmospheric cues (LaTour, Potts, \& Snook-Luther, 1990). In the shopping context, Pham et al. (2011) demonstrate that aroused individuals focus on specific features, such as prices and promotions, during the shopping trip, without responding to general cues.

With respect to the direct effects of gender on shopping behaviour, the main effect of gender is significant. This confirms previous studies that have found that women show a more favourable shopping behaviour than men (Grewal et al., 2003; Kuruvilla et al., 2009; Moye \& Kincade, 2006). Our results confirm gender stereotypes that argue that women may enjoy shopping more than men. This can be translated into a more favourable shopping behaviour, that is, higher buying, repatronage and recommending intentions. Our research proposed that women will show a greater effect of the moderating effect of mood in the relationship between atmospheric excitement and shopping behaviour. However, our findings cannot confirm these stereotypes with an only exception: the difference in the improvement of shopping behaviour in an exciting mall atmosphere for NLA shoppers is greater within women than men.

Through these findings, our paper contributes to consumer behaviour research and the retailing literature in different ways. First, we add moods as a new moderator of the effects of atmospheric excitement on shopping behaviour and analyse in depth the effect of gender. We demonstrate that arousal is an important characteristic of mood that may explain different shopping behaviours. Second, we apply mood regulation theory to the dimension of arousal in the retail context. This theory is confirmed for low-arousal moods, but not for shoppers in high-arousal moods. Our results for NLA shoppers expand Mano's (1999) work, focusing on an exciting versus a non-exciting mall atmosphere. Third, our research shows that gender is still a relevant variable to explain differences in shopper's behaviour, especially when women are exposed to an exciting atmosphere with a NLA mood. 


\subsection{Managerial implications}

Important managerial implications arise from our findings. Firstly, mall managers should be careful with the level of excitement that they try to create by designing atmospheric cues. This excitement may significantly worsen shopping behaviour for relaxed, peaceful and serene shoppers. So, managers should incorporate relaxing atmosphere zones inside the mall, trying to improve these shoppers' stay by giving them the chance of alleviating the discomfort suffered in exciting zones. Moreover, if they are not able to modify the excitement level of the mall atmosphere, they should encourage PHA moods among shoppers previous to the shopping activity, trying to change relaxation, peacefulness and calmness into enthusiasm, excitement and liveliness. In this way, the level of excitement would not worsen the behaviour of those shoppers. Additionally, although, according to our results, it is not necessary to worry about shoppers in negative moods, managers should aim to provoke positive feelings to improve their welfare. Mood manipulation is not an easy goal to reach, and previous research has not treated this question. Following Chebat et al. (2014), we propose that some promotions or events at the mall can help managers to make this manipulation. These authors found that mall visitors accompanied by a friend feel more positive feelings during their visit, which can be achieved via events or promotions that can impulse them attend the mall with friends.

Secondly, women have been considered the most important mall shoppers, and our results provide evidence that they show a more favourable behaviour while shopping, with higher purchase intentions, more intentions to recommend and enjoying the experience more. However, we have not found differences in the effects of atmospheric excitement on shopping behaviour between men and women. This may mean that gender stereotypes are disappearing within young shoppers and designers should not worry about the store atmosphere depending on it.

\subsection{Limitations and further research}

We must acknowledge several limitations in our investigation that represent opportunities for further research. Firstly, our study has been carried out in a laboratory setting with a sample which consisted of students. So, field research with a more heterogeneous sample could make our conclusions more reliable and generalizable. Additionally, new methodological techniques based on neuromarketing can be useful to analyse affective states during a trip to a mall. Secondly, we focus on mood states as moderators of the effect of atmospheric excitement on shopping behaviour, but we do not consider the different sources of these moods. Further research should address this question and try to identify their causes. Finally, our study looks into shopping activity at malls, but other retail settings could also be interesting.

\section{Acknowledgement}

The authors wish to express their gratitude for the financial support of the Spanish Government (ECO 2014-54760 and FPU 12/03240), the Government of Aragon and the European Social Fund (Generés Research Group, S09) and the program 'Ayudas a la Investigación en Ciencias Sociales Fundación Ramón Areces'. 


\section{Disclosure statement}

No potential conflict of interest was reported by the authors.

\section{Funding}

This work was supported by the Spanish Government [ECO 2014-54760], [FPU 12/03240]; the Government of Aragon and the European Social Fund [Generés Research Group, S09]; and the Fundación Ramón Areces through the program "Ayudas a la Investigación en Ciencias Sociales Fundación Ramón Areces".

\section{ORCID}

R. Pérez-López (D) http://orcid.org/0000-0001-6441-2504

\section{References}

Borges, A., Babin, B. J., \& Spielmann, N. (2013). Gender orientation and retail atmosphere: Effects on value perception. International Journal of Retail \& Distribution Management, 41, 498-511. doi: 10.1108/ IJRDM-02-2012-0014

Chebat, J. C., Haj-Salem, N. Y., \& Oliveira, S. (2014). Why shopping pals make malls different? Journal of Retailing and Consumer Services, 21, 77-85.

Das, G. (2016). Regulatory focus as a moderator of retail shopping behaviour. Journal of Strategic Marketing, 24, 484-499. doi: 10.1080/0965254X.2015.1063679

Davis, R., Lang, B., \& San Diego, J. (2014). How gender affects the relationship between hedonic shopping motivation and purchase intentions? Journal of Consumer Behaviour, 13, 18-30. doi: 10.1002/cb.1450

Di Muro, F., \& Murray, K. B. (2012). An arousal regulation explanation of mood effects on consumer choice. Journal of Consumer Research, 39, 574-584. doi: 10.1086/664040

Donovan, R. J., \& Rossiter, J. R. (1982). Store atmosphere: An environmental psychology approach. Journal of Retailing, 58(Spring), 34-57.

Fernandes, T., \& Neves, S. (2014). The role of servicescape as a driver of customer value in experiencecentric service organizations: The Dragon Football Stadium case. Journal of Strategic Marketing, 22, 548-560. doi: 10.1080/0965254X.2014.914058

Förster, J., Friedman, R. S., \& Liberman, N. (2004). Temporal construal effects on abstract and concrete thinking: Consequences for insight and creative cognition. Journal of Personality and Social Psychology, 87, 177-189. doi: 10.1037/0022-3514.87.2.177

Furnham, A., \& Milner, R. (2013). The impact of mood on customer behavior: Staff mood and environmental factors. Journal of Retailing and Consumer Services, 20, 634-641. doi: 10.1016/j. jretconser.2013.06.001

Garg, N., Inman, J. J., \& Mittal, V. (2005). Incidental and task-related affect: A re-inquiry and extension of the influence of affect on choice. Journal of Consumer Research, 32, 154-159. doi: 10.1086/426624

Gilboa, S., \& Vilnai-Yavetz, I. (2013). Shop until you drop? An exploratory analysis of mall experiences. European Journal of Marketing, 47, 239-259. doi: 10.1108/03090561311285538

Gorn, G., Pham, M. T., \& Sin, L. Y. (2001). When arousal influences ad evaluation and valence does not (and vice versa). Journal of Consumer Psychology, 11, 43-55. doi: 10.1207/S15327663JCP1101_4

Grant, I. C., \& Waite, K. (2003). "Following the yellow brick road" - Young adults' experiences of the information super-highway. Qualitative Market Research. An International Journal, 6, 48-57. doi: 10.1108/13522750310457375

Grewal, D., Baker, J., Levy, M., \& Voss, G. B. (2003). The effects of wait expectations and store atmosphere evaluations on patronage intentions in service intensive retail stores. Journal of Retailing, 79, 259-268. doi: 10.1016/j.jretai.2003.09.006

Haytko, D. L., \& Baker, J. (2004). It's all at the mall: Exploring adolescent girls' experiences. Journal of Retailing, 80, 67-83. doi: 10.1016/j.jretai.2004.01.005 
Holmqvist, J., \& Lunardo, R. (2015). The impact of an exciting store environment on consumer pleasure and shopping intentions. International Journal of Research in Marketing, 32, 117-119. doi: 10.1016/j. ijresmar.2014.12.001

Jayawardhena, C., \& Wright, L. T. (2009). An empirical investigation into e-shopping excitement: Antecedents and effects. European Journal of Marketing, 43, 1171-1187. doi: 10.1108/0309056091 0976429

Johnstone, M. L., \& Conroy, D. (2005). Dressing for the thrill: An exploration of why women dress up to go shopping. Journal of Consumer Behaviour, 4, 234-245. doi: 10.1002/cb.11

Kaltcheva, V. D., \& Weitz, B. A. (2006). When should a retailer create an exciting store environment? Journal of Marketing, 70, 107-118. doi: 10.1509/jmkg.2006.70.1.107

Kass, S. J., Beede, K. E., \& Vodanovich, S. J. (2010). Self-report measures of distractibility as correlates of simulated driving performance. Accident Analysis and Prevention, 42, 874-880. doi: 10.1016/j. aap.2009.04.012

Kemp, E., \& Kopp, S. W. (2011). Emotion regulation consumption. When feeling better is the aim. Journal of Consumer Behaviour, 10(1), 1-7. doi: 10.1002/cb.341

Kim, H., Park, K., \& Schwartz, N. (2010). Will this trip really be exciting? The role of incidental emotions in product evaluation. Journal of Consumer Research, 36, 983-991. doi: 10.1086/644763

Kotzé, T., North, E., Stols, M., \& Venter, L. (2012). Gender differences in sources of shopping enjoyment. International Journal of Consumer Studies, 36, 416-424. doi: 10.1111/j.1470-6431.2011.01060.x

Kuruvilla, S. J., Joshi, N., \& Shah, N. (2009). Do men and women really shop differently? An exploration of gender differences in mall shopping in India. International Journal of Consumer Studies, 12, 225-236. doi: 10.1111/j.1470-6431.2009.00794.x

LaTour, M. S., Potts, R. E., \& Snook-Luther, D. C. (1990). Female nudity, arousal, and ad response: An experimental investigation. Journal of Advertising, 19, 51-62. doi: 10.1080/00913367.1990.10673200

Law, D., Wong, C., \& Yip, J. (2012). How does visual merchandising affect consumer affective response? European Journal of Marketing, 46, 112-133. doi: 10.1108/03090561211189266

Luong, A. (2005). Affective service display and customer mood. Journal of Service Research, 8, 117-130. doi: $10.1177 / 1094670505279341$

Maier, E., Wilken, R., Schneider, H., \& Kelemci-Schneider, G. (2012). In the mood to buy? Understanding the interplay of mood regulation and congruence in an international context. Marketing Letters, 23, 1005-1018. doi: 10.1007/s11002-012-9200-7

Mano, H. (1999). The influence of pre-existing negative affect on store purchase intentions. Journal of Retailing, 75, 149-172. doi: 10.1016/S0022-4359(99)00002-0

Massara, F., Liu, S. S., \& Melara, R. D. (2010). Adapting to a retail environment: modeling consumerenvironment interactions. Journal of Business Research, 63, 673-681. doi: 10.1016/j.jbusres.2009.05.004

McKinney, L. N. (2004). Creating a satisfying internet shopping experience via atmospheric variables. International Journal of Consumer Studies, 28, 268-283. doi: 10.1111/j.1470-6431.2004.00368.x

Mehrabian, A., \& Russell, J. A. (1974). An approach to environmental psychology. Cambridge, MA: MIT Press.

Meloy, M. G. (2000). Mood-driven distortion of product information. Journal of Consumer Research, 27, 345-359. doi: 10.1086/317589

Meyers-Levy, J., \& Sternthal, B. (1991). Gender differences in the use of message cues and judgments. Journal of Marketing Research, 28, 84-96. doi: 10.2307/3172728

Mohan, G., Sivakumaran, B., \& Sharma, P. (2013). Impact of store environment on impulse buying behavior. European Journal of Marketing, 47, 1711-1732. doi: 10.1108/EJM-03-2011-0110

Molina, A., Martín, V. J., Santos, J., \& Aranda, E. (2009). Consumer service and loyalty in Spanish grocery store retailing: An empirical study. International Journal of Consumer Studies, 33, 477-485. doi: 10.1111/j.1470-6431.2009.00780.x

Morrison, M., Gan, S., Dubelaar, C., \& Oppewal, H. (2011). In-store music and aroma influences on shopper behavior and satisfaction. Journal of Business Research, 64, 558-564. doi: 10.1016/j. jbusres.2010.06.006

Moye, L. N., \& Kincade, D. H. (2006). Shopping orientation segments: Exploring differences in store patronage and attitudes toward retail store environments among female apparel consumers. International Journal of Consumer Studies, 27, 58-71. doi: 10.1046/j.1470-6431.2003.00260.x 
Orth, U. R., \& Wirtz, J. (2014). Consumer processing of interior service environments. Journal of Service Research, 17, 296-309. doi: 10.1177/1094670514529606

Pan, Y., \& Zinkhan, G. M. (2006). Determinants of retail patronage: A meta-analytical perspective. Journal of Retailing, 82, 229-243. doi: 10.1016/j.jretai.2005.11.008

Pham, M. T., Hung, W., \& Gorn, G. J. (2011). Relaxation increases monetary valuations. Journal of Marketing Research, 48, 814-826. doi: 10.1509/jmkr.48.5.814

Pocheptsova, A., \& Novemsky, N. (2010). When do incidental mood effects last? Lay beliefs versus actual effects. Journal of Consumer Research, 36, 992-1001. doi: 10.1086/644760

Polegato, R., \& Zaichowsky, J. L. (1994). Family food shopping: Strategies used by husbands and wives. Journal of Consumer Affairs, 28, 278-299. doi: 10.1111/j.1745-6606.1994.tb00852.x

Puccinelli, N. M., Deshpande, R., \& Isen, A. M. (2007). Should I stay or should I go? Mood congruity, selfmonitoring and retail context preference. Journal of Business Research, 60, 640-648. doi: 10.1016/j. jbusres.2006.06.014

Sherman, E., Mathur, A., \& Smith, R. B. (1997). Store environment and consumer purchase behavior: Mediating role of consumer emotions. Psychology and Marketing, 14, 361-378.

Spies, K., Hesse, F., \& Loesch, K. (1997). Store atmosphere, mood and purchasing behavior. International Journal of Research in Marketing, 14(1), 1-17. doi: 10.1016/S0167-8116(96)00015-8

Turley, L. W., \& Milliman, R. E. (2000). Atmospheric effects on shopping behavior. Journal of Business Research, 49, 193-211. doi: 10.1016/S0148-2963(99)00010-7

Van Rompay, T. J. L., Krooshoop, J., Verhoeven, J. W. M., \& Pruyn, A. T. H. (2012). With or without you: Interactive effects of retail density and need for affiliation on shopping pleasure and spending. Journal of Business Research, 65, 1126-1131. doi: 10.1016/j.jbusres.2011.08.005

Vieira, V. A., \& Torres, C. V. (2014). The effect of motivational orientation over arousal-shopping response relationship. Journal of Retailing and Consumer Services, 21, 158-167. doi: 10.1016/j. jretconser.2013.11.008

Wakefield, K. L., \& Baker, J. (1998). Excitement at the mall: Determinants and effects on shopping response. Journal of Retailing, 74, 515-539. doi: 10.1016/S0022-4359(99)80106-7

Watson, D., Clark, L. A., \& Tellegen, A. (1988). Development and validation of brief measures of positive and negative affect: The PANAS scales. Journal of Personality and Social Psychology, 54, 1063-1070. doi: 10.1037/0022-3514.54.6.1063

Wegener, D. T., Petty, R. E., \& Smith, S. M. (1995). Positive mood can increase or decrease message scrutiny: The hedonic contingency view of mood and message processing. Journal of Personality and Social Psychology, 69, 5-15. doi: 10.1037/0022-3514.69.1.5

Wirtz, J., Mattila, A. S., \& Tan, R. L. P. (2000). The moderating role of target-arousal on the impact of affect on satisfaction - An examination in the context of service experiences. Journal of Retailing, 76, 347-365. doi: 10.1016/S0022-4359(00)00031-2

Yoo, C., Park, J., \& Macinnis, D. J. (1998). Effects of store characteristics and in-store emotional experiences on store attitude. Journal of Business Research, 42, 253-263. doi: 10.1016/S0148-2963(97)00122-7

Zillman, D., Hezel, R. T., \& Medoff, N. J. (1980). The effect of affective states on selective exposure to televised entertainment fare1. Journal of Applied and Social Psychology, 10, 323-339. doi: 10.1111/ j.1559-1816.1980.tb00713.x

Zwosta, K., Hommel, B., Goschke, T., \& Fischer, R. (2013). Mood states determine the degree of task shielding in dual-task performance. Cognition \& Emotion, 27, 1142-1152. doi: 10.1080/02699931.2013.772047 


\section{Appendix}

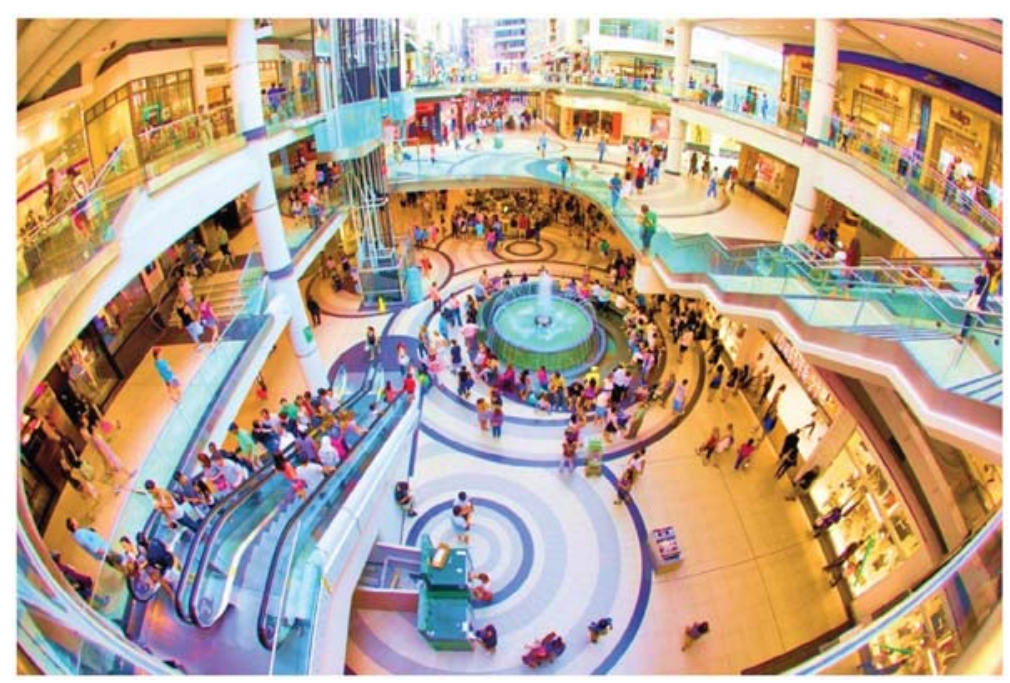

Figure A1. Exciting mall atmosphere.

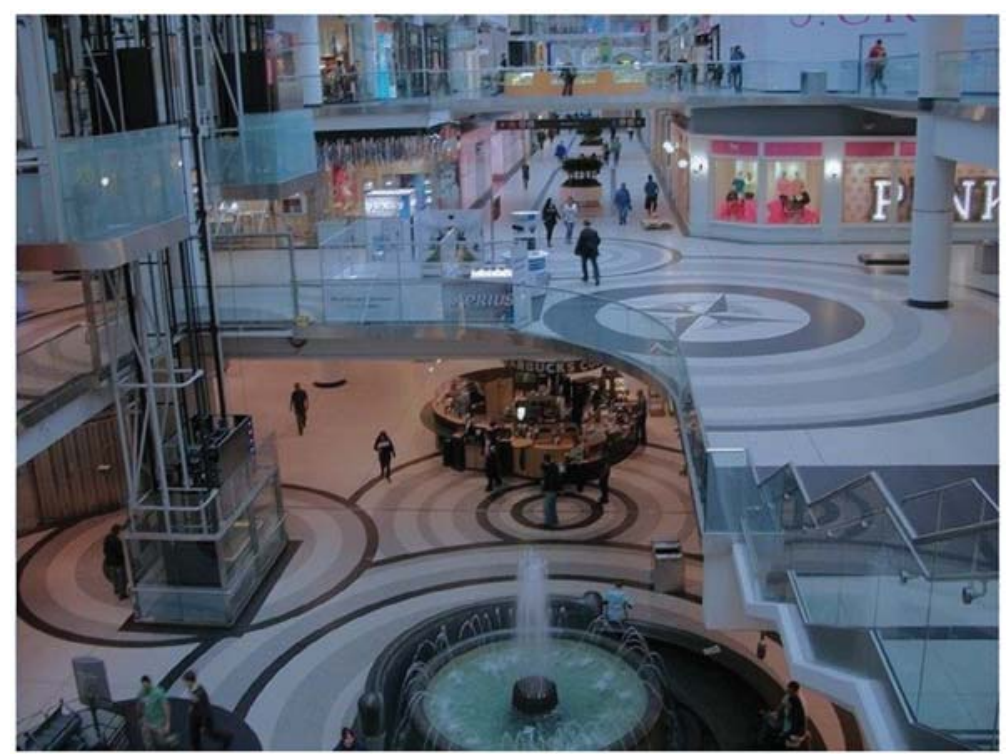

Figure A2. Non-exciting mall atmosphere. 